\title{
MAKNA TEOLOGIS DAN APLKASI DARI STRATEGI PEMBELAJARAN YAHUDI UNTUK PENDIDIKAN AGAMA KRISTEN MASA KINI
}

\author{
Yusak Tanasyah, ${ }^{1}$ Antonius Missa ${ }^{2}$ \\ Sekolah TInggi Teologi Moriah, Indonesia ${ }^{12}$ \\ Email: tanasyahyusak@gmail.com ${ }^{1}$
}

\begin{abstract}
The Jewish nation, which has been present for thousands of years in the world, has had no small influence on the development of mankind, especially in the field of education. Jews who have the same holy book or God's law as Christianity, which is sourced from the Torah, provide guidelines and implementation of how to carry out education that is applicable and useful for mankind. The Torah which is the source and guidance is a book that is taught and applied in the daily life of the Jewish people. The question is what learning strategies are used in implementing and carrying out education? Learning strategies are important to know because they involve how to bring learning to students to be more effective. Learning strategies provide content and creativity as well as core values to students to capture messages conveyed from educators to students. Christian religious education cannot escape the meaning and application of Jewish learning strategies as it has the same foundation in the law or the word of God. The method used in this study is qualitative research sourced from literature originating from books, journals, and data from internet media which is formulated to be applied for today.
\end{abstract}

Keywords: Jewish Learning Strategies, Christian Religious Education, Theology

\begin{abstract}
Abstrak
Bangsa Yahudi yang ribuan tahun hadir di dalam dunia telah memberikan pengaruh besar atas perkembangan manusia khususnya di dalam bidang Pendidikan. Yahudi yang memiliki kitab suci atau dan hukum Tuhan yang sama dengan kekristenan yang mana bersumber dari Taurat memberikan pedoman dan pelaksanaan bagaimana menjalankan pendidikan yang aplikatif dan berguna bagi umat manusia. Taurat yang adalah sumber dan petunjuk merupakan kitab yang diajarkan dan diterapkan dalam kehidupan sehari-hari umat Yahudi. Pertanyaannya adalah strategi pembelajaran apakah yang dipakai dalam menerapkan dan menjalankan pendidikan?

Strategi pembelajaran menjadi penting untuk diketahui karena menyangkut bagaimana membawa pembelajaran kepada peserta didik untuk lebih efektif. Strategi pembelajaran memberikan muatan dan kreatifitas serta nilai inti kepada peserta didik untuk menangkap pesan

yang disampaikan dari pendidik ke peserta didik. Pendidikan agama Kristen tidak dapat melepaskan diri dari makna dan penerapan dari strategi pembelajaran orag Yahudi sebagaimana memiliki pondasi yang sama di dalam hukum atau firman Allah. Metode yang digunakan dalam penelitian ini adalah penelitian kualitatif yang bersumber dari literatur yang berasal dari buku, journal dan data dari media internet yang dirumuskan untuk diambil aplikasinya bagi masa kini.
\end{abstract}

Kata Kunci: Strategi Pembelajaran Yahudi, Pendidikan Agama Kristen, Teologi 


\section{PENDAHULUAN}

Satu-satunya cara seseorang dapat memahami pendidikan Yahudi yang progresif adalah melihatnya sebagai pendidikan yang mempengaruhi afekting anak seutuhnya. Mira menguangkapkan bahwa sekolah Yahudi yang progresif tidak semata dispeme Judaica dan menawarkan berbagai macam informasi tetapi lewat pendidikan membantu membentuk sikap dan mempertajam wawasan berpikir di mana anak tinggal. ${ }^{1}$ Dalam hal ini pendidikan Yahudi memiliki makna yang menurut McKenzie,

Teaching is apprised as authoritative telling; learning is equated with listening and accepting. The faithprocess becomes the receiving of a cultural hand-me-down and not the wrestling with Jacob's angel that leads to authentic commitment. ${ }^{2}$ (Mengajar dinilai sebagai penceritaan yang berwibawa; belajar disamakan dengan mendengarkan dan menerima. Proses iman menjadi penerimaan budaya turun tangan dan bukan bergulat dengan malaikat Yakub yang mengarah pada komitmen otentik).

Menurut Roy Lowrie,

He says, "If our textbooks do not agree with the teachings of God's word, then

\footnotetext{
${ }^{1}$ Mira Stone, http://jewishcurrents.org/wpcontent/uploads/2010/02/Why-Progressive-JewishSchools-Mira-Stone.pdf diakses 4 September 2021.

${ }^{2}$ L. McKenzie, The Religious Education of Adults, (Birmingham: Religious Education Press, 1982), 21.
}

our textbooks are wrong, and God's Word is right." (II Cor. 10:3-5) He further says, "For Christian School educators, God's Word, the Bible is not on trial! But every other book, every idea of man, and every philosophy of this world is on trial. They are not on trial by our standards, but by God's standards. "3) (Dia berkata, "Jika buku pelajaran kita tidak sesuai dengan ajaran firman Tuhan, maka buku pelajaran kita salah, dan Firman Tuhan benar." (II Kor. 10:3-5) Lebih lanjut ia mengatakan, "Bagi para pendidik Sekolah Kristen, Firman Tuhan, Alkitab tidak sedang diuji! Tetapi setiap buku lain, setiap gagasan manusia, dan setiap filsafat dunia ini sedang diuji. Mereka tidak diadili oleh standar kita, tetapi oleh standar Tuhan).

Menurut Miller,

The "goal of Christian education, from a developmental point of view, is the maturity of persons." He further explicates what this means in theological language in this sentence: "The developmental approach to Christian education purposes that every person receives and respond to the grace of God in Jesus Christ; that all persons be joined together in an inclusive community, with the Spirit of mutual respect and love - in the words of Ephesians 4:13, that we might be 'measured by nothing less than the full stature of Christ." "For Miller, then, such a mature Christian is "ever more aware of God's love, ever more intentional about God's will, ever more respectful of God's providence, and ever more responsive to God's community" (Miller, Contemporary

\footnotetext{
${ }^{3}$ Ibid.
} 
Approaches, 1982, 93). ${ }^{4}$ ("Tujuan pendidikan Kristen, dari sudut pandang perkembangan, adalah kedewasaan pribadi." Lebih lanjut ia menjelaskan apa artinya ini dalam bahasa teologis dalam kalimat ini: "Pendekatan pengembangan untuk tujuan pendidikan Kristen bahwa setiap orang menerima dan menanggapi kasih karunia Allah di dalam Yesus Kristus; agar semua orang dipersatukan dalam komunitas yang inklusif, dengan Roh saling menghormati dan kasih - dalam katakata Efesus 4:13, agar kita dapat 'diukur dengan tidak kurang dari perawakan penuh Kristus."' Bagi Miller, kemudian, orang Kristen yang dewasa seperti itu "semakin sadar akan kasih Tuhan, semakin sadar akan kehendak Tuhan, semakin menghormati pemeliharaan Tuhan, dan semakin responsif terhadap komunitas Tuhan).

\section{F.F. Bruce berpendapat bahwa}

the law is described as a paidagogos -that is, a "disciplinarian." In New Testament times, a paidagogos was not a teacher, as in the modern pedagogue. His job was not to instruct the child or teach him, as a tutor or school master. Rather, he was a disciplinarian who would correct and discipline the child when he strayed from his duties. F.F. Bruce comments that "the paidagogos was the personal slave-attendant who accompanied the free-born boy wherever he went, from the time he left the nurses care... . During the boy's minority the paidagogos imposed a necessary restraint on his liberty until,

\footnotetext{
${ }^{4}$ Donald Miller, Educator. http://www2.talbot.edu/ce20/educators/view.cfm?n=d onald_miller diakses 3 September 2021.
}

with his coming of age, he could be trusted to use his liberty responsibly". ${ }^{5}$ (hukum digambarkan sebagai seorang paidagogos, yaitu seorang 'pendisiplin.' Pada zaman Perjanjian Baru, seorang paidagogos bukanlah seorang guru, seperti dalam pedagogi modern. Tugasnya bukan untuk mengajar atau mengajari anak itu, sebagai tutor atau kepala sekolah. Sebaliknya, dia adalah seorang pendisiplin yang akan mengoreksi dan mendisiplinkan anak ketika dia menyimpang dari tugasnya. F.F. Bruce berkomentar bahwa "paidagogos adalah pelayan budak pribadi yang menemani anak laki-laki yang lahir bebas ke mana pun dia pergi, sejak dia meninggalkan perawatan perawat.... Selama anak itu minoritas, paidagogo memberlakukan pembatasan yang diperlukan atas kebebasannya sampai, dengan bertambahnya usianya, dia bisa dipercaya untuk menggunakan kebebasannya secara bertanggung jawab).

Strategi pembelajaran bangsa Yahudi sejak jaman Musa hingga masa gereja mulamula miliki persamaan yang mendasar. Walaupun ada beberapa metode pembelajaran yang berubah sesuai dengan konteks waktu dan perkembangan zaman, namun inti dari strategi pembelajaran bangsa Yahudi tidak berubah. Strategi pembelajaran Yahudi berpusat pada Tuhan, hukum dan peserta didik.

${ }^{5}$ F. F. Bruce, Paul: An Apostle of the Heart Set Free. (Grand Rapids: Wm. B. Eerdmans. 1977), 67. 


\section{Strategi Pembelajaran Berbasis Hukum}

Hukum yang mana disebut sebagai firman merupakan pedoman dan aturan hidup yang mengikat kehidupan umat Yahudi. Hukum Allah dasar bagi semua yang dilakukan, diajarkan, dll, maka kita berada di tempat dimana sang pemilik hukum berkuasa. Jika kita tidak dapat membuktikan mandat yang diberikan Allah untuk Sekolah Kristen maka kita juga bisa bertanya mengapa kita harus memilikinya. Kita hidup di zaman ketika banyak orang dewasa yang tidak membuat Hukum Allah sebagai otoritas dalam hidup mereka. Jika Hukum Allah bukanlah kewenangan - lalu apa? Hukum Tuhan memiliki banyak pernyataan yang kuat untuk kebenarannya, adalah kesempurnaan, itu berasal dari Allah, itu kekuasaan dan otoritas untuk setiap aspek kehidupan. (II Tim. 3:15-17). Di dalam bukunya "Elemental Theology," ditulis oleh E. H. Bancroft, mengatakan:

"By the credibility of the Scriptures is meant that their records are true and are thus to be relied upon as the statements of the facts." "The books of the Old Testament and New Testament as we have them today are shown to have been accepted by the Church throughout the Christian era as comprising the complete revelation from God and as having been written by the human authors to whom they are accredited." 6

\section{Strategi Pembelajaran Berpusat pada Individu}

Fokus utama dari pendidikan informal adalah individu dan pertumbuhannya. Mendasari fokus ini adalah keyakinan bahwa manusia tidak hanya kapal kosong menunggu untuk diisi, seperti dalam pengajaran "model kesan" John Locke akan menyarankan, melainkan, individu adalah organisme dinamis aktif yang tumbuh dan dibentuk melalui atau keterlibatan aktif sendiri dalam belajar. Oleh karena itu, pendidikan semacam ini tempat keutamaan pada keterlibatan dan kemajuan orang itu sendiri. Dia menganggap bahwa pendidikan merupakan mitra aktif dalam dinamika pendidikan. Edukasional, ini berarti apa yang sering disebut "pedagogi yang berpusat pada anak" dalam konteks pelajar yang muda, dengan fokus pada kepentingan pribadi, mendengarkan sebanyak mengatakan, dimulai dengan pertanyaan, mengidentifikasi kepentingan, dan

\footnotetext{
${ }^{6}$ John Kwaku Opoku, Peter Addai-Mensah, Eric Manu, "Realization-of-the-Nature-and-Role-ofChristian-Education-in-Modern-Pedagogy." British Journal of Education 2, no.5 (October 2014): 26-35. https://www.eajournals.org/wpcontent/uploads/Realization-of-the-Nature-and-Roleof-Christian-Education-in-Modern-Pedagogy.pdf
} 
berkolaborasi daripada memaksakan pendidikan.

Dalam hal pendidikan Yahudi informal, berpusat pada prinsip orang yang berarti membantu setiap individu tumbuh dan menemukan makna sebagai seorang Yahudi. Penekanannya adalah pada pembangunan pribadi Yahudi daripada transmisi budaya Yahudi, dan orang tersebut adalah aktif terlibat dalam perjalanannya sendiri menuju pertumbuhan Yahudi. Keasyikan dengan orang Yahudi dalam pendidikan informal yang juga menyiratkan kekhawatiran bahwa akan mempengaruhi jumlah pembelajar mereka. Sementara kegiatan yang dapat dipilih dapat berfokus pada keterampilan khusus untuk orang Yahudi atau topik Yahudi (seperti belajar berbicara bahasa Ibrani atau membangun Sukkah), tujuan utama pendidikan Yahudi informal membangun orang itu karakter Yahudi secara keseluruhan. Dengan demikian, pendidikan formal Yahudi tidak melihat "pertumbuhan Yahudi" sebagai intelektual eksklusif melainkan sebagai sintesis estetika, afektif, moral, perilaku, dan dimensi kognitif. ${ }^{7}$

\footnotetext{
${ }^{7}$ Chazan Barry, Experience Jewish Education http://jewishstudies.washington.edu/wpcontent/uploads/2015/05/Philosophy-of-InformalJewish-Ed-Chazan.pdf diakses 12 Oktober 2021.
}

\section{Strategi pembelajaran berdasarkan nilai}

Kurikulum umumnya dipandang sebagai karakteristik formal daripada pendidikan formal dan dipahami dalam hal mengatur program studi, dengan daftar mata pelajaran, buku untuk dibaca, ide-ide yang harus dipelajari, dan tes yang akan diberikan. Namun, konsep generik kurikulum sebagai keseluruhan cetak biru atau rencana tindakan yang sangat banyak merupakan bagian dari pendidikan Yahudi. Dalam kehidupan orang Yahudi kontemporer ada perbedaan pandangan mengenai inti pengalaman dan nilai-nilai tradisi atau budaya Yahudi. Pendekatan agama cenderung untuk menekankan doa, studi, liburan, dan ritual. Pendekatan etnis cenderung menekankan Ibrani, liburan, musik, dan adat istiadat. Pendekatan nasional cenderung menekankan Tanah Israel, melakukan perjalanan ke Israel, Ibrani, dan sejarah Yahudi. Karena keragaman ini, sulit untuk tiba pada satu kesepakatan kurikulum inti untuk mengajar pengalaman dan nilai-nilai. Namun, ada beberapa pengalaman Yahudi yang tampaknya bersama oleh sebagian besar sistem pendidikan formal Yahudi: (1) libur Yahudi dan pengalaman kalender, (2) 
pengalaman siklus hidup Yahudi, (3)

mempelajari teks-teks Yahudi,

Pengalaman budaya dan keumatan Yahudi, dan (5) bertindak pada nilai-nilai Yahudi.

Dimensi pusat kurikulum pendidikan formal Yahudi adalah fleksibilitas dan dinamis. Metode pengajaran "isi inti" dan urutan di mana mereka diajarkan terbuka untuk perubahan dan penyesuaian. Ini pengalaman inti dan nilai-nilai dapat harus "diajarkan" dalam berbagai cara, tergantung pada waktu, tempat, dan kecepatan masingmasing setiap peserta didik. Pendidikan Yahudi berakar pada keyakinan bahwa pendidikan pada akhirnya tentang "menciptakan budaya" daripada transmisi pengetahuan. Bentuk pendidikan mencapai tujuan yang paling efektif dengan memperlakukan seluruh lingkungan pendidikan sebagai komprehensif budaya. "Budaya" di sini mengacu pada totalitas komponen yang membentuk pendidikan konteks: arsitektur, gaya pakaian, kode dan norma-norma perilaku, pola tempat duduk, dekorasi fisik dan estetika, norma interaksi manusia, pola bahasa, dan banyak others. ${ }^{8}$ Menurut teori psikologi budaya, itu adalah total budaya lingkungan yang mengajarkan, dengan menghadirkan, menciptakan, dan

\footnotetext{
${ }^{8}$ Jerome Bruner, The Culture of Education (Cambridge: Harvard University Press, 1996), 13.
}

memperkuat nilai-nilai, ide, pengalaman, norma, dan akhirnya pandangan dunia.

Pendidikan Yahudi berfokus pada semua aspek lingkungan dalam rangka mendidik untuk Yahudi. Ini tidak hanya menekankan isi kognitif atau diskursif, tetapi juga banyak aspek beragam pengaturan secara keseluruhan: apa yang tampak seperti; makanan apa yang disajikan dan bagaimana, apa yang terjadi saat istirahat, bagaimana anggota staf berinteraksi dengan satu sama lain. Dengan pendekatan seperti itu, pertimbangan logistik dan organisasi yang tidak insidental atau sekunder untuk program pendidikan, mereka sendiri masalah inheren pendidikan. Masalah makanan, perjalanan, tidur dan bangun, kebersihan pribadi, dan ekonomi adalah masalah inti pendidikan dan kesehatan mental dan bukan dari masalah logistik dan administration. ${ }^{9}$

Gagasan "budaya pendidikan" juga menyiratkan bahwa pendidikan tidak terbatas pada lokasi tertentu seperti ruang kelas atau gedung sekolah, yang dapat terjadi di mana saja. Seperti yang kita belajar yang paling ringkas dan paling kuat teks pada pendidikan informal yang pernah

\footnotetext{
${ }^{9}$ Fritz Redl dan David Wineman, The Aggressive Children (Glencoe, Illinois: Free Press, 1957), 14.
} 
Yahudi ditulis, pendidikan Yahudi terjadi "ketika Anda duduk di rumah Anda, ketika Anda berjalan dengan jalan, saat Anda berbaring, dan ketika Anda bangkit "(Ulangan 6: 4-9). Gagasan tentang budaya pendidikan juga menunjukkan bahwa tidak ada lembaga yang memiliki monopoli pendidikan Yahudi. Budaya seperti itu dapat dibuat di mana pun orang Yahudi ditemukan: di pusat-pusat komunitas, kantor pelayanan keluarga Yahudi, dan klub olahraga, pada retret dan konferensi; selama makan dan naik bus. Beberapa tempattempat ini juga mungkin ideal tempat untuk pendidikan Yahudi karena mereka adalah nyata pengaturan di mana pengalaman Yahudi dapat hidup keluar. Tugas pendidik adalah untuk membentuk semua pengaturan sehingga mereka dapat melayani visi pendidikan yang lebih besar

\section{Strategi Pembelajaran Proses Interaktif}

Pada akhirnya terungkapnya kurikulum ditentukan oleh interaksi orang satu sama lain dan dengan pengalaman inti. Pendidikan Yahudi berakar pada keyakinan bahwa pertukaran aktif antara peserta didik dan antara peserta didik dan pendidik merupakan dimensi penting dari pembelajaran Yahudi. Interaksi mengacu pada timbal balik efek atau pengaruh antara dua orang atau lebih. Perilaku satu, diasumsikan, bertindak sebagai stimulus bagi perilaku lainnya. Orang belajar dan tumbuh melalui aktif interaksi sosial, yang merangsang ide-ide, menyebabkan kita untuk berpikir dan memikirkan kembali pandangan, dan membantu kita untuk kembali konsep keyakinan dan ideologi. Aktif kembali di dalam berdialog dengan orang lain bukan hanya pedagogis berguna, adalah, dalam arti yang lebih dasar, faktor penting dalam membentuk ide-ide, keyakinan, dan behaviors. ${ }^{10}$ Prinsip interaktivitas menyiratkan pedagogi mengajukan pertanyaan, merangsang diskusi, dan menarik pelajar. Untuk merangsang interaktivitas, pendidik harus menciptakan lingkungan yang mengundang peserta didik untuk mendengarkan satu sama lain dan untuk bereaksi dengan martabat dan kesopanan. ${ }^{11}$ Pedagogi pendidikan Yahudi berakar dalam teknik yang memerdekakan keterbukaan, mendorong keterlibatan, menghasut dialektika kreatif, dan menjamin kenyamanan keragaman dan perbedaan

\footnotetext{
${ }^{10}$ Martin Buber, "Pengajaran dan Akta," di Israel dan Dunia (New York: Schocken, 1948) 81.

${ }^{11}$ Common, Dianne L. "Conversation as A Pedagogy of Reform for Public Education." The Journal of General Education 43, no. 4 (1994): 24172. http://www.jstor.org/stable/27797232.
} 
pendapat. Misalnya, siswa dapat bertanya apa yang mereka pikirkan, bagaimana rabi besar masa lalu mungkin bereaksi, apa artinya isi Yahudi untuk hidup mereka, dan apa mereka setuju atau tidak setuju dengan. Pendidikan Yahudi peduli dengan memicu dialogis dengan peserta didik seperti halnya dengan transmisi budaya. Pendidik Yahudi tidak bisa benar-benar menyelesaikan pekerjaan mereka kecuali ada proses interaktif dinamis antara siswa dan pendidik, pelajar dan mahasiswa, mahasiswa dan teks, dan siswa dan tradisi. Baik terus terang maupun instrumental, interaksi ini adalah melekat unsur teori pendidikan Yahudi formal tentang belajar.

\section{Strategi Pembelajaran Pengalaman}

Kelompok

Dalam pendidikan, kelompok merupakan komponen integral dari pengalaman belajar. Sebagaimana Emile Durkheim dan GH, Mead berpendapat, kelompok adalah kekuatan apriori yang membentuk kehidupan manusia, ${ }^{12}$ daripada struktur teknis yang ditumpangkan pada kita. Kelompok yang kita bentuk adalah bagian pikiran, bahasa, dan diri kita. Oleh karena itu, kelompok mengajar bukan hanya

\footnotetext{
${ }^{12}$ Emile Durkheim, Education and Sociology (Glencoe, Illinois: Free Press, 1957) 12.
}

tentang transmisi pengetahuan untuk semua individu berkumpul dalam satu ruangan, melainkan sangat banyak tentang peran dinamis dari kolektif dalam mengekspresikan dan memperkuat nilainilai yang merupakan bagian dari budaya masyarakat yang membentuk kelompok. Kelompok tidak hanya orang belajar individual secara paralel, mereka adalah jaringan sosial yang mengajarkan ide-ide dan nilai-nilai melalui esensi dari proses kelompok.

Dengan demikian, kelas pembelajaran Yahudi tidak hanya kelas individu memperluas pengetahuan Yahudi mereka, itu adalah sebuah komunitas dinamis dewasa yang berpikiran berbagi pengetahuan, pengalaman, nyeri, kegembiraan, dan saatsaat bersama. Pendidik Yahudi tidak hanya mengajarkan sejarah atau hari libur Yahudi, dia juga membentuk sebuah komunitas yang mencontohkan nilai Yahudi kehilla. Kelompok ini sentral dalam pendidikan Yahudi bahwa nilai-nilai kunci klal Yisrael (totalitas Israel), am Yisrael (orang Yahudi), kehillat kodesh (komunitas suci), dan tikkun olam (meningkatkan dunia) dialami melalui keberadaannya. Beberapa telah melihat asosiasionalisme Yahudi sebagai semacam identitas kesukuan yang eksklusif atau 
asosiasi dapat dimengerti, tetapi ada juga kekuatan besar positif sebagai kesadaran kolektif Yahudi komunal, sebagaimana dibuktikan oleh keterlibatan Yahudi di gerakan Soviet Yahudi dan gerakan hak-hak sipil di Amerika Serikat, serta dukungan Yahudi untuk bangsa Israel selama bertahun-tahun. Pendidikan Yahudi berupaya untuk memanfaatkan kekuatan itu. ${ }^{13}$ Pendidikan Yahudi berakar pada keyakinan bahwa pengalaman adalah pusat pembangunan pribadi Yahudi. Gagasan pengalaman di bidang pendidikan berasal dari gagasan bahwa berpartisipasi dalam suatu peristiwa atau sesaat melalui indera dan tubuh memungkinkan seseorang untuk memahami konsep, fakta atau keyakinan secara langsung dan tanpa perantara. Pengalaman dalam pendidikan mengacu pada pembelajaran yang terjadi melalui partisipasi dalam kegiatan atau melalui tindakan langsung lainnya, atau dengan pengamatan langsung atau pendengaran.

John Dewey memperluas ide ini dengan menyatakan bahwa belajar paling baik jika mereka aktif bukan pasif terlibat dalam mengalami ide atau suatu peristiwa. Mengalami seperti berakar dalam interaksi

\footnotetext{
${ }^{13}$ Robert Bellah, et al, Habits of the Heart: Individualism and Commitment in American Life (Berkeley: University of California Press, 1985) 20.
}

gagasan atau peristiwa dengan kehidupan seseorang dan dengan kontinum ide yang memungkinkan pengalaman untuk kontribusi pertumbuhan berlangsung. Fokus pribadi pada hasil pengalaman dalam pedagogi yang mencoba untuk membuat pengaturan yang memungkinkan nilai yang akan dialami secara pribadi dan peristiwa yang akan dialami secara waktu riil dan di tempat-tempat asli, bukannya mereka sedang dijelaskan untuk pelajar. Selama bertahun-tahun gagasan ini mengalami telah menjadi erat diidentifikasi dengan "pengalaman pendidikan, "sering dianggap sebagai" kartu panggil "dari education. Dalam hal pendidikan Yahudi pembelajaran informal terjadi melalui kemungkinkan orang untuk menjalani pengalaman kunci dan nilai-nilai Yahudi. Sebagai contoh, pendekatan pengalaman untuk Sabat berfokus pada memungkinkan orang untuk mengalami Sabat secara waktu riil - Jumat sore, menyalakan lilin saat matahari terbenam, mendengar kiddush sebelum makan, dan makan Hallah. Pendekatan ini tidak menyangkal nilai belajar tentang Sabat di kelas dan dari teks tetapi tidak menunjukkan bahwa belajar kognitif tentang pengalaman tidak bisa menggantikan hal yang nyata. 
Pendidikan Yahudi intens terlibat dan bahkan peserta yang diundang dan membuat mereka merasa positif tentang keterlibatan mereka. Karena fokusnya pada individu dan pada isu-isu yang nyata kepadanya, pendidikan Yahudi sering digambarkan sebagai "Menyenangkan," "menyenangkan," atau "menyenangkan." ${ }^{14}$ Ini tidak harus diambil sebagai tanda kesembronoan atau kurangnya keseriusan. Sebagai Erikson dan lain-lain telah mengajarkan kita, identitas adalah sebagian rasa perasaan positif tentang kelompok atau kerangka acuan, dan perasaan positif tentang Pengalaman Yahudi memainkan peran penting dalam pengembangan identitas Yahudi. Memang, ada orang yang mengatakan bahwa kita perlu pengalaman seperti itu karena Yahudi perkembangan identitas begitu sering dipersulit oleh sejumlah asosiasi negatif. Penelitian poin pendidikan Yahudi informal ke tingkat tinggi peserta kepuasan dibandingkan dengan bidang-bidang lain dari kehidupan Yahudi.

Dalam konteks ini, pendidikan formal Yahudi dapat dibandingkan untuk bermain dan olahraga. Literatur tentang bermain dan olahraga menekankan keterlibatan dan keterlibatan pihak pelajar, sukacita di saat

\footnotetext{
${ }^{14}$ Van Clive Morris, Existentialism in Education (New York: Harper dan Row, 1966), 78.
}

ini, kedekatan itu semua, memori positif, dan asosiasi hangat. ${ }^{15}$ Para pendidik Yahudi total dalam kepribadian pendidikan yang mendidik dengan kata-kata, perbuatan, dan dengan membentuk budaya nilai-nilai Yahudi dan pengalaman. Dia adalah para pendidik Yahudi yang merupakan pembentuk pengalaman Yahudi. Perannya dalam konteks adalah untuk menciptakan peluang bagi pengalaman dan untuk memfasilitasi pelajar masuk ke momen.

$$
\text { Para pendidik Yahudi yang }
$$
mempromosikan interaksi dan interchange. Salah satu tugas utama dia adalah untuk menciptakan lingkungan yang memungkinkan ini interaktivitas untuk berkembang. Hal ini membutuhkan kemahiran dalam keterampilan mengajukan pertanyaan, mendengarkan, dan mengaktifkan keterlibatan orang lain. Para pendidik Yahudi merupakan pencipta masyarakat dan kehilla: ia/dia membentuk kebersamaan ke dalam kelompok dan memanfaatkan pengaturan kelompok untuk mengajarkan inti seperti Yahudi nilai-nilai sebagai klal Yisrael (keumatan Yahudi), kvod haadam (martabat semua orang), shutfut goral (takdir bersama), dan shivyon (kesetaraan). Pendidik Yahudi pencipta

\footnotetext{
${ }^{15}$ Saralea Chazan, Profile Play (London dan
} Philadelphia: Jessica Kingsley Publishers. 2002), 94. 
budaya, mereka peka terhadap semua elemen khusus untuk pendidikan pengaturan sehingga ini akan mencerminkan nilai-nilai dan pengalaman yang mereka ingin menyampaikan. Tugas dalam hal ini adalah untuk membuat setiap keputusan besar atau kecil-keputusan pendidikan.

Pendidik Yahudi harus mampu melibatkan orang-orang dengan siapa mereka bekerja dan membuat pengalaman belajar mereka menyenangkan. Stimulasi asosiasi positif bagian dari pekerjaan pendidik informal yang Yahudi itu. Akhirnya, pendidik Yahudi yang perlu menjadi Yahudi berpendidikan dan berkomitmen. Pendidik ini harus berpengetahuan karena salah satu dari nilainilai yang atau dia datang untuk mengajar adalah talmud torah pengetahuan-Yahudi. Dia harus berkomitmen untuk nilai-nilai sejak mengajar komitmen kepada orangorang Yahudi, dengan kehidupan Yahudi, dan nilai-nilai Yahudi di jantung dari perusahaan. Komitmen hanya bisa dipelajari jika seseorang melihat contoh itu tutup. Pendidikan Yahudi ditujukan pada pertumbuhan pribadi orang Yahudi dari segala usia. Itu terjadi melalui individu yang aktif mengalami keragaman saat Yahudi dan nilai-nilai yang dianggap berharga. Ia bekerja dengan menciptakan tempat, oleh mengembangkan budaya pendidikan total, dan dengan mengkooptasi konteks sosial. Hal ini didasarkan pada kurikulum nilainilai Yahudi dan pengalaman yang disajikan secara dinamis dan cara yang fleksibel.

\section{Aplikasi Strategi Pembelajaran Yahudi terhadap Pendidikan Agama Kristen Masa Kini}

"Setiap sekolah yang dilihat - publik atau swasta, agama atau sekuler - adalah pengingat yang terlihat dari agama Yesus Kristus. Demikian juga setiap perguruan tinggi dan universitas, kata James Kennedy dan Jerry Newcombe dalam tulisan mereka dalam buku "What If Jesus Never Been Born?" buku fenomena pendidikan yang berakar pada kekristenan. Mengejar pengetahuan Allah secara sistematis, filosofis dan mendalam memunculkan fenomena universitas di seluruh dunia. Itu adalah iman Kristen yang memunculkan gagasan pendidikan tinggi. Kekristenan adalah kekuatan yang luar biasa untuk pendidikan. Sebagian besar bahasa di dunia yang diatur pertama tertulis oleh misionaris Kristen. Buku pertama dalam kebanyakan bahasa di dunia telah menjadi Alkitab. Kekristenan telah menjadi kekuatan terbesar 
untuk mempromosikan keaksaraan di seluruh dunia sepanjang sejarah, termasuk di Indonesia. $^{16}$ Berpusat pada Kristus menyatakan bahwa pendidikan konten untuk pendidikan Kristen harus selaras dengan ajaran Alkitab. (II Tim. 3:16-17; Mzm. 119:128; Mzm. 119.) Strategi antipatif ini merupakan usaha untuk menjembatani perubahan eksternal yang terjadi dengan kondisi internal yang dipresentasikan oleh sumber daya, kapabilitas dan kompetensi yang dimiliki. ${ }^{17}$ Pembelajaran Kristen terdiri dari pembentukan, pemeliharaan, dan pengembangan identitas baru itu, yang aslinya adalah Yesus Kristus, yang, sebagai gambar Allah, adalah pola kemanusiaan yang ditebus. Oleh karena itu, tujuan pendidikan Kristen adalah keselarasan individu dan kelompok dengan Kristus. ${ }^{18}$ Ini menyediakan dasar untuk integrasi dan

\footnotetext{
${ }^{16}$ Kennedy James, Newcombe Jerry, http://americanaction.us/index.php/othermatters/book-reviews/what-if-jesus-had-never-beenborn-by-d-james-kennedy; Yoseti Gulo dan Widjaja Sugiri. "Pengaruh Guru Pendidikan Agama Kristen Terhadap Pelayanan Remaja Dalam Konteks Gereja Di Indonesia (The Influence Of Christian Religion Education Toward Teenagers Services In The Context Of Churches In Indonesia)". QUAERENS:

Journal of Theology and Christianity Studies 2, no.2 (2020): 86-101. https://doi.org/10.46362/quaerens.v2i2.22.

${ }^{17}$ Wiryoputro Sugiyanto, Dasar-dasar Manajemen Kristen. (Jakarta BPK Gunung Mulia. 2001), 37.

${ }^{18}$ Heywood David, Human Learning. http://www.davidheywood.org/humanlearning/PDF/I ntroduction.pdf
}

korelasi semua materi pelajaran. Setiap subjek diajarkan dengan Kristus sebagai pusat. Instruksi mengambil makna baru saat subyek diinterpretasikan dalam terang Firman Tuhan. Apa yang Tuhan katakan? Sejarah menjadi kisah Allah berurusan dengan manusia. Geografi tempat dimana kita hidup seperti yang Anda lihat Injil tersebar di seluruh negara yang berbeda. Sains adalah pekerjaan dari hukum-hukum Allah. Matematika menunjukkan kemutlakan Tuhan. Pancasila dan Kewarganegaraan menunjukkan pandangan Allah tentang budaya dunia, pemerintah, dan masalah. Kesehatan kita melihat bahwa manusia dahsyat dan ajaib. ${ }^{19}$

\section{KESIMPULAN}

Dengan demikian, sekarang tidak mampu memahami Pendidikan Agama Kristen tanpa bantuan Firman Allah (hukum Tuhan). Tujuan dari Pendidikan Kristen dipandang manusia tunduk sadar seluruh bumi untuk kemuliaan Allah, dan mata pelajaran yang dianggap tidak hanya orang Kristen dan terutama anak-anak mereka. Sang Guru pendidikan Kristen selalu Tuhan,

\footnotetext{
${ }^{19}$ Kennedy James, Newcombe Jerry, http://americanaction.us/index.php/othermatters/book-reviews/what-if-jesus-had-never-beenborn-by-d-james-kennedy/ diakses 17 November 2021
} 
sekarang beroperasi paling utama melalui orangtua tetapi juga melalui perjanjian komunitas dan atau melalui gereja dan sekolah dan negara - dan para pendidik. Sedangkan metode pendidikan Kristen ditemukan bervariasi dari ibadah keluarga dan mengucapkan puji syukur di meja dan membaca Alkitab dan Sekolah Minggu dan kehadiran gereja, untuk metode yang digunakan di sekolah-sekolah Kristen seperti prinsip-prinsip penilaian dan individualitas

\section{KEPUSTAKAAN}

Bettelheim, Bruno. Love is Not Enough. New York: Collier Books, 1950.

Bruce, F. F. Paul: An Apostle of the Heart Set Free. Grand Rapids: Wm. B. Eerdmans, 1977.

Bruner, Jerome. The Culture of Education. Cambridge: Harvard University Press, 1996.

Buber, Martin. "Teaching and Act," in Israel and World. New York: Schocken, 1948.

Burbules, Nicholas C. Dialogue in Teaching: Theory and Practice. New York: Teachers College Press, 1993.

Chazan, Barry. The Philosophy of Informal Jewish Education. Israel: Jewish Agency for Israel, 2002. https://www.policyarchive.org/handle/1 0207/10084.

Cole, Michael. Cultural Psychology. Cambridge, Mass: Harvard University Press, 1996.

Durkheim, Emile. Education and Sociology. Glencoe, Illinois: Free Press, 1957.

Durnbaugh, Donald F. "Contributions to Christian Education." In Donald Eugene Miller. dan disiplin terhadap universalitas dosa dan realitas perjanjian kasih karunia - namun selalu sadar akan fakta bahwa semua metode hanyalah sarana untuk satu-satunya akhir memuliakan Allah. Pemahaman yang berdasarkan dari pendidikan Yahudi ini yang terus dikembangkan dalam pendidikan agama Kristen untuk mewujudkan kemanusiaan manusia yang menjalankan tugas untuk bersekutu bersama dengan Tuhan, sesama dan alam ciptaan Tuhan.

http://www2.talbot.edu/ce20/educators/ view.cfm?n=donald_miller.

Giamatti, A. Bartlett. A Great and Glorious Game. Chapel Hill: Algonquin, 1998.

Gulo, Yoseti dan Widjaja Sugiri. "Pengaruh Guru Pendidikan Agama Kristen Terhadap Pelayanan Remaja Dalam Konteks Gereja Di Indonesia (The Influence Of Christian Religion Education Toward Teenagers Services In The Context Of Churches In Indonesia)". QUAERENS: Journal of Theology and Christianity Studies 2, no.2 (2020): 86-101. https://doi.org/10.46362/quaerens.v2i2. 22.

Haroutinian-Gordon, S. Managing the Soul: Teaching Through Conversation in High School. Chicago: University of Chicago Press, 1991.

Heywood, David. "Revelation and Christian Learning." in Christian ministry, Bible study, adult education and ministerial formation. Ashgate, 2004. http://www.davidheywood.org/humanle arning/PDF/Introduction.pdf 
Kennedy, D. James dan Newcombe Jerry. "If Jesus had never been born." American Action. http://americanaction.us/index.php/othe r-matters/book-reviews/what-if-jesushad-never-been-born-by-d-jameskennedy/

Kohlberg, Lawrence. Philosophy of Development Moral. San Francisco: Harper dan Row, 1981.

McKenzie, L. The Religious Education of Adults, Birmingham, Ala.: Religious Education Press, 1982.

Mead, G.H. Mind, Self and Society. Chicago: University of Chicago Press, 1934.

Putnam, Robert dan Bowling Alone. The Collapse and The Awakening of Society America. New York: Simon dan Schuster, 2000.

Redl, Fritz dan David Wineman. The Aggressive Children. Glencoe, Illinois: Free Press, 1957.
Robert Bellah, et al. Habits of the Heart: Individualism and Commitment in American Life. Berkeley: University of California Press, 1985.

Saralea Chazan. Profile Play. London dan Philadelphia: Jessica Kingsley Publishers, 2002.

Stone, Mira. "Why Progressive Jewish Schools." Jewish Currents. http://jewishcurrents.org/wpcontent/uploads/2010/02/WhyProgressive-Jewish-Schools-MiraStone.pdf

Van Clive, Morris. Existentialism in Education. New York: Harper dan Row, 1966.

Wiryoputro Sugiyanto. Dasar-Dasar Manajemen Kristen. Jakarta BPK Gunung Mulia, 2001.

Wright, Robert. The Animal Moral. New York: Vintage Books, 1994. 